\title{
Stage IVA Vaginal Cancer AJCC v8
}

National Cancer Institute

\section{Source}

National Cancer Institute. Stage IVA Vaginal Cancer A/CC v8. NCI Thesaurus. Code C139669.

Stage IVA includes: T4, Any N, M0. T4: Tumor invading the mucosa of the bladder or rectum and/or extending beyond the true pelvis (bullous edema is not sufficient evidence to classify a tumor as T4). M0: No distant metastasis. (from AJCC 8th Ed.) 